\title{
Um jogador patológico por Dostoiévski
}

\author{
A pathological gambler by Dostoyevsky
}

\author{
Fernando Machado Vilhena Dias ${ }^{1}$, Hugo Alejandro Cano-Prais ${ }^{2}$, Sérgio Kehdy ${ }^{3}$, Antônio Lúcio \\ Teixeira $^{4}$
}

${ }^{1}$ Médico psiquiatra, Pós-Graduação em Neurociências, Universidade Federal de Minas Gerais (UFMG), Belo Horizonte, MG. ${ }^{2}$ Médico psiquiatra. Professor, Universidade Federal de Ouro Preto (UFOP), Ouro Preto, MG. ${ }^{3}$ Médico psiquiatra e psicanalista. ${ }^{4}$ Médico psiquiatra e neurologista. Professor, Faculdade de Medicina, UFMG, Belo Horizonte, MG.

\section{Resumo}

O livro "O jogador" de Fiódor Dostoiévski narra um caso de jogo patológico bastante representativo. O percurso do personagem principal, Aleksei Ivanovitch, evidencia a dramática evolução do transtorno com três fases bem definidas: ganho, perdas e desespero. Partindo do conceito freudiano de narcisismo articulado aos conceitos da psicologia do self de Heinz Kohut, das teorias de Donald Winnicott e Wilfred Bion, serão discutidas as contribuições da psicanálise para a compreensão do jogo patológico.

Descritores: Jogo patológico, Dostoiévski, psicanálise, narcisismo.

\begin{abstract}
Dostoyevsky's book, "The gambler," describes a representative case of pathological gambling. The history of the main character, Aleksei Ivanovitch, shows the typical evolution of the disorder in three well defined phases: profits, losses and despair. Based on Freud's concept of narcissism and the concepts of the self psychology by Heinz Kohut, Donald Winnicott and Wilfred Bion, the contributions of psychoanalysis to the understanding of pathological gambling are discussed.
\end{abstract}

Keywords: Pathological gambling, Dostoyevsky, psychoanalysis, narcissism.

\section{Introdução}

O jogo patológico, uma entidade clínica bastante intrigante, é o tema principal da obra "O Jogador", do escritor russo Fiódor Dostoiévski ${ }^{1}$. O autor, um notório epilético, reconhecido por seu vigor na descrição das vivências psicológicas dos personagens, relata com precisão o sofrimento associado ao jogo patológico. O próprio Dostoiévski era, provavelmente, um jogador compulsivo e, assolado por dívidas, necessitando cumprir um contrato com seu editor, escreve o romance em apenas vinte e seis dias, conferindo-lhe, assim, um tom autobiográfico ${ }^{2}$.

Em 1928, Sigmund Freud publica um artigo intitulado "Dostoiévski e o parricídio", formulando as primeiras compreensões psicanalíticas sobre o jogo patológico ${ }^{3}$. Posteriormente, outros psicanalistas, como Otto Fenichel, Heinz Kohut, Donald Winnicott e Wilfred Bion, contribuíram para a ampliação das teorias sobre a condição, articulando conceitos freudianos, como o de narcisismo, ao jogo patológico.

Neste artigo, os autores apresentam inicialmente uma súmula do livro "O Jogador" de Dostoiévski, salientando alguns trechos para caracterizar e exemplificar o jogo patológico. Posteriormente, são apresentadas e discutidas possíveis contribuições da psicanálise à compreensão do jogo patológico.

\section{Correspondência:}

Fernando Machado Vilhena Dias, Rua Deputado Álvaro Sales, 276/301, Santo Antônio, CEP 30350-250, Belo Horizonte, MG. E-mail: fernandomvdias@hotmail.com 


\section{Súmula do livro "O jogador"}

Aleksei Ivanovitch, personagem principal e narrador da obra, exerce a atividade de preceptor de uma tradicional família russa que se encontra em uma estação de águas alemã denominada sugestivamente de "Roletemburgo".

A família, com a qual Aleksei convive intimamente, acompanhando a educação das crianças, apresenta algumas particularidades interessantes. O patriarca, um general russo completamente falido, precisa fugir de seu país devido a dívidas. Viúvo, o general se apaixona por Mademoiselle Blanche, uma linda jovem francesa que se utiliza da beleza para garantir o sustento. $\mathrm{O}$ general deposita a esperança de viver esse amor na eminente morte de sua velha e rica "avozinha", de quem seria o único herdeiro. Polina, enteada do general, é amada platônica e submissamente por Aleksei. Assim, Polina manipula Aleksei para tentar livrar-se do francês Des Grieux, seu pretendente, que sustenta a família na expectativa de um futuro casamento.

Ao longo de todo o romance, nota-se baixa tolerância a frustrações e impulsividade em Aleksei, o que afeta de forma negativa suas relações interpessoais. Em determinado momento, por exemplo, ao cruzar na rua com um poderoso barão alemão, incomodado simplesmente com a posição social superior desse, Aleksei o agride verbalmente. Frente à reclamação do barão e à necessidade de preservar a imagem, o general demite o preceptor.

Entrementes, a família do general aguardava um telegrama comunicando a morte da "avozinha", que fora acometida de uma grave doença. Porém, a "avozinha" recupera-se milagrosamente e decide ir a Roletemburgo. O seu único anseio era jogar e escolhe o desempregado Aleksei como tutor do jogo. A experiência da "avozinha" na roleta retrata parte da desgraça relacionada ao jogo patológico, de tal maneira que vale um adendo no relato das vicissitudes de Aleksei. Na sua primeira incursão na roleta, após várias tentativas e ao atingir uma espécie de transe, ganha bastante dinheiro. Decide interromper o jogo, mas comunica que retornaria posteriormente. $\mathrm{O}$ narrador antevê a sucessão de acontecimentos catastróficos posteriores: "Agora que a avozinha realizava tais façanhas na roleta, agora que a personalidade da avozinha se impusera junto a eles com tamanha nitidez (...) Agora, talvez, tudo estivesse perdido: pois estava contente como uma criança e ia certamente ser depenada no jogo". De fato, a "avozinha" entrou em um processo no qual o jogo era interrompido somente para obter mais dinheiro, dilapidando sua fortuna.

Polina, ao saber da derrocada da "avozinha", vai ao encontro de Aleksei e declara perversamente o seu amor por ele. Aproveita a oportunidade para pedir ajuda para se livrar de Des Grieux. Invadido por um sentimento intenso, Aleksei junta as economias e decide tentar a sorte. No cassino, Aleksei faz tentativas audaciosas, ganhando bastante dinheiro. Constata, no entanto: "Não me lembro de ter pensando uma só vez em Polina aquela noite. Experimentava um prazer extraordinário em reunir e recontar as notas (...)”. Mas Aleksei desperta, resolve interromper o jogo e vai ao encontro de Polina que, de forma inesperada, refuta-o.

Mademoiselle Blanche, ciente do feito de Aleksei na roleta, convida-o para acompanhá-la a Paris. Em estado de inércia afetiva, ele aceita o convite. Em Paris, Aleksei gasta, em pouco mais de um mês de extravagâncias, os ganhos provenientes do jogo. Nesse mesmo período, consumia freqüentemente champanha para atenuar o sentimento de tristeza que o assolava. Finalmente, sente-se livre para sair em campanha pelas roletas da Europa.

Assim, "mais de um ano e meio se passou desde então, e estou, a meu ver, muito pior do que um mendigo". Foi preso por dívidas decorrentes do jogo, tornou-se lacaio e trabalhou em troca de comida. Quando possível, retornava à roleta para perder tudo novamente. Tentava convencer a si próprio com argumentos tais como: "posso descobrir o homem em mim, antes que ele se perca (...). Arriscando mais que a minha vida, eu ousava ariscar (...) e eis-me de novo incluído entre os homens".

Um conhecido, ao reencontrá-lo em Roletemburgo, observa: "Não somente se afastou da vida, de seus interesses próprios e dos interesses sociais, de seus deveres de homem e de cidadão, de seus amigos (pois os tinha), não somente se afastou de todo e qualquer objetivo que não seja o de ganhar, como até mesmo de suas recordações (...)". O conhecido se despede e lhe doa uma pequena soma de dinheiro, apenas o suficiente para alimentá-lo. Ele aceita a generosidade, porém, perde-se em meio a seus pensamentos. "Veio-me um pressentimento, e não poderia deixar de ser assim (...). Será possível que seja criança a esse ponto? Será que não compreendo que sou um homem perdido? Mas, por que não poderia ressuscitar? Bastaria por uma vez ter caráter, e numa hora poderia mudar toda a minha vida".

\section{Discussão}

O jogo patológico é classificado atualmente entre os transtornos de impulso. Caracteriza-se por preocupação com o jogo e com a obtenção de dinheiro para jogar, incapacidade de controlar o comportamento do jogo, mesmo frente a nítidas conseqüências adversas sócio-ocupacionais e/ou legais ${ }^{4}$. 
Os critérios diagnósticos do jogo patológico assemelham-se sobremaneira aos dos transtornos de abuso de substâncias psicoativas, constituindo um modelo de comportamento aditivo, mas sem a presença da droga ${ }^{4,5}$. Modelos alternativos a esse vêm sendo propostos no sentido de compreender a complexidade relacionada ao transtorno ${ }^{5,6}$. Por exemplo, alguns autores consideram-no uma entidade do espectro obsessivo-compulsivo ${ }^{5}$. Outros, em virtude da elevada comorbidade com transtornos do humor, aproximamno do espectro bipolar ${ }^{7}$. Nesse sentido, é interessante notar a similaridade entre os ciclos depressão-mania do transtorno bipolar e os estados de humor do jogador que está perdendo e ganhando, respectivamente. Correlacionando os comportamentos exibidos por Aleksei ao longo da narrativa com os modelos da gênese do jogo patológico, constata-se, além da considerável impulsividade, a presença de tendência à adição ao álcool e, sobretudo, a instabilidade do seu humor, alternando nitidamente fases de euforia e desânimo ${ }^{5-7}$.

Ao final do romance, Aleksei exibe todas as características clínicas que permitem diagnosticá-lo como jogador patológico ${ }^{4}$. Demonstra preocupação e atividade pessoal dirigidas exclusivamente ao jogo, mesmo com as inúmeras perdas financeiras e sociais, além dos problemas legais. Para atingir esse ponto, Aleksei vivenciou as três fases características da evolução do jogo patológico: fase de ganhos, na qual o jogador consegue controlar o impulso para jogar, permitindo algum ganho com o jogo; fase de perdas, em que o impulso para jogar se torna mandatório, interferindo na capacidade de avaliação e repercutindo em prejuízos financeiros; e fase de desespero, na qual o jogador apresenta prejuízos significativos em várias dimensões de sua vida pessoal ${ }^{4}$. A própria "avozinha" percorreu essas três fases em tempo bastante curto, o que é descrito como efeito "telescópio", ocorrendo mais comumente em mulheres ${ }^{8}$.

As contribuições iniciais da psicanálise para a compreensão do jogo patológico podem ser encontradas nos escritos freudianos. Em "Dostoiévski e o parricídio", Freud sugeriu que os jogadores impulsivos, como o próprio autor russo, teriam um desejo inconsciente de perder, jogando para aliviar o sentimento de culpa ${ }^{3}$. Assim, argumentava que “(...) todos os pormenores de sua conduta impulsivamente irracional demonstram isso. Ele nunca descansava antes de ter perdido tudo. Para ele, o jogo era também um método de autopunição" 3 . Freud também associou o jogar impulsivo ao ato masturbatório, delineando as primeiras idéias que vinculam o jogo patológico ao complexo de Édipo e suas estruturas correlatas (superego, ego ideal e ideal de ego), e suas relações com o narcisismo. Freud finaliza o artigo teorizando a sina do romancista: "Se a inclinação ao jogo, com suas lutas mal-sucedidas para romper o hábito, e as oportunidades que proporciona para autopunição, constitui uma repetição a se masturbar, não nos surpreenderemos em descobrir que tal inclinação tenha ocupado um espaço tão grande na vida de Dostoiévski”"

Otto Fenichel reafirmou as fantasias masturbatórias infantis como associadas ao jogo patológico, vinculando-as também ao parricídio. Acrescentou que muitos atos impulsivos tendem a expressar não somente pulsões instintivas, mas também exigências de um superego tirânico9 ${ }^{9}$. Segundo esse autor, à semelhança dos estados maníacodepressivos, os jogadores impulsivos experimentam períodos de culpa intensa que se alternam com período de aparente não atuação do superego ${ }^{9}$. Fenichel argumenta ainda que a função psicológica do jogo não-patológico seria a liberação do indivíduo das pressões externas, mediante a repetição ou a antecipação dessas. No entanto, no jogo patológico, sob pressões internas violentas, o ego oprimido entraria em um círculo vicioso de angústia e necessidade de seguranças contínuas?.

Mas quais seriam as pressões internas referidas vagamente por Otto Fenichel? Retomando o texto freudiano, chega-se ao narcisismo, definido como a estase da libido que nenhum investimento de objeto consegue ultrapassar completamente ${ }^{10}$. Freud distingue duas formas de narcisismo: um estado narcísico primitivo (anobjetal) ou primário e o narcisismo secundário ${ }^{11}$. $\mathrm{O}$ narcisismo primário seria caracterizado pela total ausência de relação com o meio, devido à indiferenciação entre o ego e o id. Por sua vez, o narcisismo secundário seria o narcisismo do ego investido nos objetos ${ }^{11}$.

$\mathrm{O}$ narcisismo secundário origina o ideal de ego, aquilo que determina o que deveríamos ser e atingir. $\mathrm{O}$ ideal de ego representa, portanto, uma formação narcísica resultante da convergência do narcisismo (idealização do ego) e das identificações parentais com seus substitutos ou ideais coletivo ${ }^{11}$. Ressalta-se que Freud diferencia o ideal de ego do superego, correlacionando o sentimento de culpa ao superego e o sentimento de inferioridade ao ideal de ego, uma vez que este último é mais amado do que temido ${ }^{11}$.

$\mathrm{O}$ ego precisa ser admirado pelo ideal de ego. $\mathrm{Na}$ situação de um ideal muito elevado, o ego jamais se sentirá suficiente. Assim, todos os êxitos conseguidos serão insuficientes e a vivência do vazio e da inutilidade estará presente, determinando o tédio ${ }^{12}$. Portanto, caso a relação entre o ego e o ideal do ego não seja harmônica, há ameaça constante das sensações de vazio e de inutilidade, que são combatidas por alguns indivíduos com manobras potencialmente 
perigosas, incluindo o jogo, o uso de drogas e o comprar compulsivo.

Em relação à análise especifica dos transtornos narcísicos, grupo no qual se encaixaria o jogo patológico, Heinz Kohut enfatiza a importância de os pacientes revivenciarem e elaborarem as letargias, depressões e raivas dos primórdios da vida a partir da transferência de seus relacionamentos arcaicos e traumáticos do self com o objeto do self ${ }^{13}$. Nesses casos, a mobilização das experiências da mais remota infância deveria ocupar o centro do palco analítico por períodos prolongados. Em termos clínicos, quando não recebe as respostas de afirmação e validação que busca nas pessoas com quem se relaciona, o self poderia fragmentar-se. Como forma de lidar com essa fragmentação e reconquistar a coesão do self, surgiriam os comportamentos impulsivos, como o jogar patológico. Kohut utiliza o termo "objeto do self" para designar o objeto que atua como espelho do indivíduo, designando-o e regulando a ansiedade não diretamente vinculada à auto-estima ${ }^{13}$.

A função dos "objetos do self" de Kohut de regulação de ansiedades aproxima-se dos conceitos de "reverie" de Bion ${ }^{14}$ e da "mãe suficientemente boa" de Winnicot ${ }^{15}$. Considerando a função da mãe de harmonizar física e emocionalmente os estágios de desenvolvimento da criança, protegendo-a inicialmente das angústias arcaicas e, em seguida, oferecendo um distanciamento que permite a diferenciação entre o eu do não-eu, a função dos "objetos do self" é essencial para o indivíduo adulto suportar suas vicissitudes.

Assim, o jogo patológico como um transtorno narcisista poderia ser entendido como uma experiência de satisfação substitutiva. Em uma situação narcísica angustiante, o sujeito recorreria às experiências prazerosas, no caso, o jogar. Uma vez estabelecida essa articulação, criar-se-ia uma defasagem de significação entre as experiências de medo, tristeza e desvalorização, e da satisfação que segue o jogar. É essa defasagem que estaria na base da repetição da experiência de satisfação do jogar patológico, bem como de outras formas de adições, explicando ainda a dificuldade relacionada ao tratamento dessas condições. Em suma, o jogador ficaria à mercê da sua onipotência quando está jogando e, conseqüentemente, haveria a mobilização contínua do seu narcisismo. Os indivíduos conhecidos como "aqueles que não sabem perder" são pessoas para quem a derrota ou a vitória tomam um significado extremo. No jogador patológico, as vitórias e as derrotas têm um sentido de "vida e morte", e o jogo assume papel central na manutenção da vida psíquica do indivíduo.

O exemplo de Dostoiévski é interessante, pois sua paixão patológica pelo jogo evoluiu paralelamente ao seu percurso sentimental ${ }^{2}$. O amor dedicado a Polina
Suslova, curiosamente o mesmo nome dado à personagem do livro "O jogador", é paradigmático das relações que Dostoiévski estabelecia com seus "objetos de self". Ela o abandonara para ficar com um espanhol, o que levou Dostoiévski a viajar pela Europa. Entretanto, Dostoiévski não foi em busca de sua amada, deixando-se ficar na Alemanha, em um dos cassinos mais em voga da época. Dizia para si próprio que queria ganhar bastante dinheiro para reconquistar Polina. Quando a encontrou, Polina roubou-lhe todo o dinheiro conquistado na roleta. Afogado em dívidas e abatido com a morte do irmão predileto, Dostoiévski começa a vender sua obra. Em um último esforço, decidiu ditar o romance "O Jogador" a uma estenografa, Ana Grigorievna, com quem se casaria mais tarde.

No livro, Aleksei era uma pessoa sem história, que servia à família nobre russa para sobreviver e que não se conformava com sua condição de inferior. Assim, sentia-se atormentado com a sua própria imagem. Quando fala de Polina, por exemplo, mulher que escolheu como objeto de desejo, fica evidente sua fantasia de que, possuindo-a, seria resgatado enquanto pessoa de valor. Tenta, então, existir em função dela, que, no entanto, manipula-o e rejeita-o mesmo quando ele ganha. Polina não lhe confere a oportunidade ou a saída de existir através do outro. A busca por paz interna, ou seja, por momentos em que não tinha que se preocupar com seu equilíbrio narcísico, faz com que aceite a proposta da Mademoiselle Blanche de ir a Paris, mesmo sabendo que estava sendo explorado. $\mathrm{O}$ dinheiro em si não tinha importância, contando apenas o fato de ter sido aceito. Ao deixar Paris, seu desespero volta aos níveis anteriores, quando seus recursos internos não são suficientes para manter um mínimo de integração e de sentimento de valor. Redescobre, então, o jogo e se torna um jogador contumaz, buscando, a cada volta da roleta, recuperar alguma crença em si mesmo. Toda sua vida torna-se um ponto: jogar e jogar compulsivamente. A regressão de Aleksei a um funcionamento narcísico arcaico chega a magnitude tal, que as demais funções vitais são desprezadas. No final, o personagem encontra-se miserável e faminto, mas prefere trocar a moeda oferecida pelo amigo para se alimentar por mais uma tentativa de sobreviver com as voltas da roleta.

A complexidade do jogo patológico permite vários níveis de interpretação e entendimento complementares, incluindo as diferentes formulações conceituais do transtorno no campo dos distúrbios do impulso, de comportamentos aditivos, do espectro obsessivo-compulsivo e mesmo outras leituras psicodinâmicas. Dostoiévski retrata magistralmente as desventuras de um jogador com as várias nuances psicopatológicas do transtorno, possibilitando ainda antever os aspectos psicodinâmicos envolvidos. 


\section{Referências}

1. Dostoiévski F. O jogador. Brasil: Editora 34; 2004.

2. Schnaiderman B. Posfácio: notas sobre um jogador. In: Dostoiévski F. O jogador. Brasil: Editora 34; 2004. p. 217-25.

3. Freud S. Dostoievski y el parricídio. In: Obras completas de Sigmund Freud. vol. XXI. Buenos Aires: Santiago Rueda; 1928.

4. Sood ED, Pallanti S, Hollander E. Diagnosis and treatment of Pathologic Gambling. Curr Psychiatry Rep. 2003;5(1):9-15.

5. Dell'Osso B, Altamura AC, Allen A, Marazziti D, Hollander E. Epidemiologic and clinical updates on impulse control disorders: a critical review. Eur Arch Psychiatry Clin Neurosci. 2006;256(8):464-75.

6. Dannon PN, Lowengrub K, Gonopolski Y, Musin E, Kotler M. Pathological gambling: a review of phenomenological models and treatment modalities for an underrecognized psychiatric disorder. Prim Care Companion J Clin Psychiatry. 2006;8(6):334-9.
7. McElroy L, Pope G, Keck E. Are impulsive-control disorders related to bipolar disorders? Compr Psychiatry. 1996;37(4):229-40.

8. Zilberman M, Tavares H, el-Guebaly N. Gender similarities and differences: the prevalence and course of alcohol- and other substance-related disorders. J Addict Dis. 2003;22(4):61-74.

9. Fenichel O. Teoria psicoanalítica de las neurosis. Buenos Aires: Paidos; 1966.

10. Freud S. Introducción al narcisismo. In: Obras completas de Sigmund Freud. vol. XIV. Buenos Aires: Santiago Rueda; 1914.

11. Freud S. El Yo y el Ello. In: Obras completas de Sigmund Freud. vol. IX. Buenos Aires: Santiago Rueda; 1923.

12. Chasseguet-Smirgel, J. O ideal do ego. Porto Alegre: Artmed; 1992.

13. Kohut H. Psicologia do self e a cultura humana. Porto Alegre: Artmed; 1988.

14. Bion WR. Attention and Interpretation. London: H. Karnac; 1970.

15. Winnicott DW. Explorações psicanalíticas. Porto Alegre: Artmed; 1989. 